\title{
Pain in patients with panic disorder: Relation to symptoms, cognitive characteristics and treatment outcome
}

\author{
Norman B Schmidt PhD ${ }^{1}$, Helen T Santiago PhD², John H Trakowski PhD², \\ J Michael Kendren BS
}

\begin{abstract}
NB Schmidt, HT Santiago, JH Trakowski, JM Kendren. Pain in patients with panic disorder: Relation to symptoms, cognitive characteristics and treatment outcome. Pain Res Manage 2002;7(3):134-141.
\end{abstract}

OBJECTIVE: Although there has been a link between certain types of pain, notably chest pain, and panic disorder, the relation between pain and panic disorder has not been systematically evaluated. In the present study, the relation between pain symptoms (headache, chest pain, stomach pain, joint pain) and the clinical presentation of patients with panic disorder was evaluated.

HYPOTHESES: Pain was generally hypothesized to be related to increased symptoms of anxiety, panic-relevant cognitive domains and treatment outcome. In terms of specific pain domains, headache and chest pain were expected to be more closely related to anxiety-related symptoms.

PARTICIPANTS AND METHODS: Patients ( $\mathrm{n}=139)$ meeting the criteria of the Diagnostic and Statistical Manual of Mental Disorders - Fourth Edition for panic disorder completed a set of standardized clinician-rated and self-reported measures. Moderator analyses were used in a subset of these patients completing a treatment outcome study.

RESULTS: Approximately two-thirds of the participants endorsed at least one current pain symptom. The hypotheses were partially supported, with pain being associated with higher levels of anxiety and depression symptoms, as well as panic frequency. Pain was also related to several cognitive features, including anxiety sensitivity and panic appraisals. Headache and chest pain were more highly associated with anxiety symptoms than was joint pain. Cognitive measures did not mediate the relation between anxiety and pain, and pain did not significantly moderate outcome in response to cognitive-behavioural therapy.

CONCLUSIONS: Co-occurring pain symptoms appear to be more highly related to phenomenology than to treatment response in patients with panic disorder.

Key Words: Anxiety; Cognitive function; Pain; Panic disorder; Treatment

La douleur chez les patients présentant un trouble panique : La relation aux symptômes, les caractéristiques cognitives et les résultats du traitement

OBJECTIF : Bien qu'il existe un lien entre certains types de douleur, notamment les douleurs thoraciques et le trouble panique, la relation entre la douleur et le trouble panique n'a pas été évaluée de manière systématique. Dans la présente étude, on a évalué le lien entre les symptômes de douleur (maux de tête, douleurs thoraciques, maux d'estomac, douleurs articulaires) et la présentation clinique des patients atteints d'un trouble panique. HYPOTHÈSES : Il a été postulé qu'en général, la douleur est reliée à une augmentation des symptômes d'anxiété, des domaines cognitifs associés à la panique et des résultats du traitement. Pour ce qui est des foyers précis de la douleur, on prévoyait que les maux de tête et les douleurs thoraciques seraient davantage associés aux symptômes anxiogènes.

voir page suivante

${ }^{1}$ Department of Psychology, The Ohio State University, Columbus, Ohio; ${ }^{2}$ National Space Biomedical Research Institute, Houston, Texas; ${ }^{3}$ Adult Outpatient Psychology Service, Dwight D Eisenhower Army Medical Center, Fort Gordon, Georgia; ${ }^{4}$ Laboratory for Anxiety and Stress Disorders, The Ohio State University, Columbus, Ohio, USA

Correspondence and reprints: Dr Norman B Schmidt, Department of Psychology, 245 Townshend Hall, The Ohio State University, Columbus, Ohio 43210-1222, USA. Telephone 614-292-2687, fax 614-688-8261, e-mail schmidt.283@osu.edu 
PARTICIPANTS ET MÉTHODOLOGIE : Les patients (n=139) respectant les critères du Manuel diagnostique et statistique des troubles mentaux, quatrième édition, en matière de trouble panique, ont subi une série de mesures normalisées à la fois évaluées par le clinicien et autoévaluées. Des analyses de modérateur ont été utilisées dans un sous?groupe de ces patients qui participaient à une étude sur les résultats des traitements. RÉSULTATS : Environ les deux tiers des participants affichaient au moins un symptôme de douleur. Les hypothèses ont été partiellement vérifiées, la douleur étant associée à des niveaux plus élevés d'anxiété et de symptômes de dépression, ainsi qu'à la fréquence de la panique. La douleur s'associait également à plusieurs fonctions cognitives, y compris la sensibilité à l'anxiété et aux évaluations de la panique. Les maux de tête et les douleurs thoraciques étaient davantage reliées aux symptômes d'anxiété que les douleurs articulaires. Les mesures cognitives n'ont pas assuré la médiation entre l'anxiété et la douleur, et la douleur n'a pas modéré les résultats de la réaction de manière marquée par suite d'une thérapie cognitivocomportementale.

CONCLUSIONS : Des symptômes cooccurrents de douleur semblent être reliés davantage à la phénoménologie qu'à la réaction au traitement des patients atteints de trouble panique.
$E^{v}$ idence from epidemiological data indicates that panic disorder is a prevalent and debilitating condition associated with significant adverse social, marital and financial consequences (1). Moreover, patients with panic disorder appear to overuse medical facilities (2,3). For example, because the symptoms of panic disorder overlap with those of cardiovascular disease, many patients with panic disorder present initially to an emergency room or physician's office (4). Routine electrocardiographic assessment frequently fails to find a physical basis for symptoms such as chest pain, and physicians often do not recognize the presence of panic. Further complicating this situation is evidence that patients with chest pain and microvascular angina, both of which can occur in patients with angiographically normal coronary arteries, may have a higher than expected prevalence of panic disorder (5).

Anxiety has generally been associated with pain and different types of pain disorders $(6,7)$. The relation between anxiety and pain has been studied fairly extensively. Many early reports confirmed a relation between higher levels of anxiety and increased pain $(8,9)$. More specifically, panic disorder has been associated with an increased frequency of pain complaints. For example, it appears that almost $40 \%$ of patients with panic disorder are bothered by some form of persistent pain (10); the most common pain complaints are headache and chest pain $(3,10)$.

Although an association between pain and panic disorder exists, the underlying mechanisms for this linkage have not been well explored. In the case of chest pain, which is perhaps the best-studied pain domain in patients with panic disorder $(11,12)$, the specific nature of this relation is open to speculation. It has been proposed, for example, that at least some patients with panic disorder and angiographically normal coronary arteries who experience chest pain may suffer from microvascular angina resulting from the constriction (possibly due to catecholamine release secondary to anxiety) of small resistance vessels within the heart wall that are not visualized angiographically (13).

An alternative explanation for the link between pain and panic disorder that applies to other pain domains is that anxiety leads to increased pain sensitivity. Thus, patients with anxiety disorders may report pain more often because of greater pain sensitivity resulting from their anxiety. Tests of this hypothesis have had ambiguous results. Some studies have found that trait anxiety was not related to pain sensitivity (14). Other results have indicated that anxiety may some- times decrease pain sensitivity and sometimes increase pain sensitivity $(15,16)$. In the case of panic disorder specifically, at least one study found that patients with panic disorder had normal pain sensitivity relative to that of matched control subjects (17). However, in a more recent study (18), patients reported greater pain reactivity to a cold pressor challenge (ie, patients reported greater amounts of pain during the challenge) relative to that of matched control subjects. This relation was found to be mediated by a cognitive variable termed 'anxiety sensitivity'.

Anxiety sensitivity is the extent to which an individual believes that symptoms of anxiety or arousal can have harmful consequences (19). Individual differences in anxiety sensitivity are hypothesized to emerge from the combined influences of genetic variation and any number of experiences that ultimately lead to the acquisition of beliefs about the potentially aversive consequences of arousal (20). Such experiences may include hearing others express fear of such sensations, receiving misinformation about the harmfulness of certain sensations, witnessing a catastrophic physical event such as a heart attack, etc. Evidence that anxiety sensitivity is a risk factor for anxiety and anxiety disorders is accumulating from both experimental studies and prospective studies (2123).

Although the majority of research concerning anxiety sensitivity has centred on anxiety disorders, researchers have recently begun to examine the role of anxiety sensitivity in other conditions, including pain. Exploration of the relations between anxiety and pain has been spurred by findings suggesting that there is a high degree of comorbidity between chronic pain and anxiety disorders (24). Individuals with chronic pain tend to be more anxious than nonclinical populations, and patients with panic disorder frequently report significant and persistent pain $(25,26)$.

Asmundson and colleagues (27) suggested that anxiety sensitivity may play a role in the onset and or maintenance of chronic pain via fear of pain and avoidance behaviours $(24,27,28)$. They suggested that because anxiety sensitivity marks an individual's general propensity to develop fears, it may amplify a specific tendency to develop fear of pain. Fear of pain, in turn, increases pain-related escape and avoidance behaviours, which have been proposed to be important mechanisms of pain maintenance (29-31). More specifically, negative expectancies regarding the harmfulness of pain are amplified by anxiety sensitivity, causing avoidance behaviours; these avoidance behaviours lead to 
deconditioning (eg, muscular atrophy, reduction in activity and weight gain). Deconditioning leads to increased pain, which heightens avoidance and exacerbates negative expectancies regarding pain (32). Thus, anxiety sensitivity is believed to be a key factor in the maintenance of pain and disability by enhancing the reciprocal relation between fear and avoidance.

In summary, the relation between pain and panic disorder has not been adequately evaluated. We sought to clarify this relation both by replicating earlier work and by extending this literature. First, we were interested in replicating earlier findings indicating that pain symptoms resulted in a different clinical presentation in patients with panic disorder (10). We extended this work by evaluating the relation between specific pain symptoms and clinical domains (eg, chest pain and headache versus joint pain). We speculated that chest pain and headache pain would be more highly associated with anxiety symptomatology relative to other pain domains (eg, joint pain) because of the greater likelihood that patients with panic disorder would catastrophically misinterpret these symptoms - consistent with recent cognitive accounts of panic disorder, as well as the fact that patients with panic disorder commonly report fears of cardiovascular and cerebrovascular events (33). Chest pain and headache are more likely to lead to fear of an immediate catastrophic consequence (eg, "There is something wrong with my heart", "I'm having a stroke") than is joint pain (eg, "I'm going to need hip replacement surgery").

Second, we were interested in examining the relation between pain and panic-related cognitive domains such as anxiety sensitivity. We are aware of only one other report that has conducted such an analysis (10), and that report found elevated anxiety sensitivity among patients with panic disorder who endorsed chronic pain relative to those who did not. We were also interested in extending this literature by testing whether anxiety sensitivity might mediate the relation between anxiety symptoms and pain symptoms.

Finally, we were interested in determining whether pain symptoms affected treatment response in patients with panic disorder. Conceivably, increased pain may adversely affect treatment response to a psychosocial intervention for panic (ie, cognitive behavioural therapy).

\section{Participants}

\section{PARTICIPANTS AND METHODS}

Clinical sample: The clinical sample comprised 147 participants who met the following criteria:

- principal diagnosis of panic disorder according to the criteria of the Diagnostic and Statistical Manual of Mental Disorders, Fourth Edition (DSM-IV) (34);

- no change in medication type or dose during the past eight weeks;

- no evidence of serious suicide intent;

- no evidence of current substance abuse;
- no evidence of current or past schizophrenia or bipolar disorder;

- no medical history of respiratory disease, renal disease, heart disease, epilepsy or stroke; and

- between the ages of 18 and 65 years.

Diagnostic assessment was based on a structured diagnostic interview using the Structured Clinical Interview for the DSM (SCID) (35). Interviews were conducted by advanced graduate students studying clinical psychology with extensive training in SCID administration and scoring. Each interview was reviewed by a licensed clinical psychologist during weekly staff meetings in a manner consistent with that of previous studies showing that this procedure results in high overall inter-rater reliability and high inter-rater agreement for panic disorder diagnoses $(36,37)$. Medication status and medical history were similarly assessed using a semistructured clinical interview. Following the diagnostic and medical history interviews, participants completed self-report measures.

\section{Measures}

A multimodal assessment battery tapping the major clinical dimensions of panic disorder was administered to all participants. This battery consisted of clinician-rated measures of panic frequency, intensity, anticipatory anxiety, avoidance and impairment (Multicenter - Panic Anxiety Scale [MCPAS]), as well as self-rated measures of anxiety (Sheehan Patient-Rated Anxiety Scale [SPRAS]), phobic avoidance (Mobility Inventory [MI]), disability (Sheehan Disability Scale [SDS]) and depression (Beck Depression Inventory [BDI]). In addition, self-report ratings of subjective pain were taken from a semistructured medical history interview.

Subjective pain assessment: During an intake evaluation, all participants completed a semistructured medical history interview assessing their history of physical illness and current symptom complaints. Four questions from the semistructured medical history interview were used to index subjective pain. These questions had a dichotomous response format, in which the patient endorses the presence or absence of headache, ulcer/stomach pain, chest pain and joint pain. Individual responses to these items were evaluated in the present report. In addition, a composite, dimensional measure was formed corresponding to the number of pain domains endorsed by the patient (range zero to four).

MC-PAS: The MC-PAS (formerly the CY-PAS) is a semistructured interview rating scale for panic disorder that includes ratings of panic frequency and intensity; anticipatory anxiety, and avoidance of sensations and situations; and impairment in work and social functioning (38). Each of these symptoms is rated on a scale of 0 (none) to 4 (extreme). The MC-PAS has good psychometric properties (38). In the present sample, two clinicians in a dual interview making MC-PAS ratings for a subsample $(\mathrm{n}=25)$ were found to have consistently high reliability ( $\mathrm{r}$ range $=0.71$ to 0.94 ).

SPRAS: The SPRAS is a self-report scale that is widely used for assessing the intensity of anxiety symptoms (39). It has 
demonstrated adequate test-retest reliability $(\mathrm{r}=0.67)$ and is highly associated with other measures of anxiety and overall impairment in samples of patients with panic disorder (36).

MI: The MI was used to assess phobic avoidance (40) and includes two subscales for determining the level of phobic avoidance when alone ('MI-Alone') and when accompanied ('MI-Accompanied'). The subscales are scored separately and have been found to possess good psychometric properties in clinical samples (40).

SDS: The SDS is a four-item, self-report measure of impairment created by the presenting problem (41). One representative item from this scale that taps the overall work and social impairment was used in the present report. This item is associated with clinical, global ratings of impairment and quality of life in samples of patients with panic disorder (26). BDI: Level of depressive symptoms was assessed by the $\mathrm{BDI}$, which is a reliable and well-validated measure of depressive symptomatology (42).

Anxiety Sensitivity Index: The Anxiety Sensitivity Index (ASI) is a 16-item questionnaire that measures fear of arousal symptoms (43). Each item assesses concern about the possible negative consequences of anxiety symptoms. The ASI has demonstrated adequate psychometric properties (43). Moreover, the ASI appears to tap fear of anxiety symptoms as opposed to state or trait anxiety (44).

Panic Appraisal Inventory: The Panic Appraisal Inventory (PAI) is a 45-item self-report measure composed of three separate scales assessing related aspects of panic appraisal, including estimates of panic likelihood across a variety of settings (PAI-Likelihood), perceived catastrophic consequences of experiencing panic (PAI-Consequences) and coping self-efficacy in the context of panic (PAICoping). The PAI-Consequences scale is further divided into three subscales assessing physical, social and loss of control threats. Each of the PAI subscales possesses high internal consistency (coefficient $\alpha s=0.85$ to 0.94 ) and testretest reliability ( $\mathrm{rs}=0.81$ to 0.89 ), and is predictive of phobic avoidance and general symptom severity among patients with panic disorder $(45,46)$.

\section{Sample description}

\section{RESULTS}

The sample of patients with panic disorder who participated in the present study was predominantly white $(85 \%)$ and female $(67 \%)$, with a mean age of 35.7 years (SD 11.5 years). The majority were currently employed $(80 \%)$ and married $(55 \%)$. Sixty-one per cent of the sample received an agoraphobia diagnosis, $43 \%$ received a co-occurring anxiety disorder diagnosis and $24 \%$ received a co-occurring mood disorder diagnosis. It is also notable that only one patient received a somatoform diagnosis (undifferentiated somatoform disorder). A substantial number of patients (53\%) were taking psychotropic medications for their anxiety problems. Of these patients, $32 \%$ were taking antidepressants, $45 \%$ were taking benzodiazepines, $22 \%$ were taking both antidepressants and benzodiazepines, and $1 \%$ were taking other types of medication (eg, beta-blockers).

\section{Pain endorsement}

Endorsement of the four pain domains indicated a fairly high prevalence of pain reports. Only 29\% of the sample reported experiencing no current pain symptoms, 28\% reported pain in one domain, $24 \%$ reported pain in two domains, $13 \%$ reported pain in three domains and 5\% reported pain in all four domains. The mean score on the continuous measure of pain was 1.4 (SD 1.2). The most common complaint was headache (55\%), followed by chest pain (34\%), joint pain (25\%), and stomach pain or ulcer (22\%).

\section{Pain and demographic variables}

The relation between pain domains (chest, headache, joint, stomach) and demographic factors was analyzed using $t$ tests for continuous measures and $\chi^{2}$ tests for dichotomous measures. Due to the number of analyses conducted in this study, a more conservative $\mathrm{P}$ value was used $(\mathrm{P}<0.01)$ to control for type I error. Findings indicated nonsignificant trends for pain domains related to age. Pain reports were not significantly related to sex, marital status or employment status. There was one significant finding for ethnicity, with headaches being more frequently endorsed by white participants $(62 \%)$ than by black, hispanic or other groups (overall $19 \%)\left(\chi^{2}[3,139]=14.2, \mathrm{P}<0.01\right)$. As a result, ethnicity was statistically controlled for in later analyses of headache symptoms.

\section{Pain and diagnostic/symptom variables}

The relations between pain domains and the more common co-occurring diagnoses (ie, agoraphobia, any additional anxiety diagnosis, any additional mood diagnosis) were evaluated, and no significant associations were indicated. Pain domain was not associated with medication type $(P>0.01)$. Table 1 shows the relation between specific pain domains and symptoms. To summarize these findings, pain endorsement was generally associated with higher levels of anxiety symptoms and depression symptoms (eg, correlations between the continuous anxiety scale and SPRAS $[\mathrm{r}=0.43, \mathrm{P}<0.0001]$, BDI $[\mathrm{r}=0.39, \mathrm{P}<0.0001])$. Panic frequency (CY-PAS) was also generally associated with pain $(\mathrm{r}=0.25, \mathrm{P}<0.01)$. On the other hand, pain was not associated with level of phobic avoidance, disability, anticipatory anxiety or distress during panic.

Results of the specificity analyses were consistent with expected values. Joint pain was not significantly associated with any symptom measure. All of the other pain domains were associated with anxiety symptoms as well as depression. In addition, headaches were associated with increased panic frequency, and stomach and chest pain were associated with avoidance of physical sensations.

\section{Pain and panic-relevant cognitive variables}

The overall association between pain and the cognitive parameters was significant, with pain being related to higher levels of anxiety sensitivity $(\mathrm{r}=0.26, \mathrm{P}<0.01)$, perceptions of diminished coping capacity with respect to panic (PAI-3: $r=-0.22, \mathrm{P}<0.01)$ and increased expectations 
TABLE 1

Relation between pain endorsement and symptoms in patients with panic disorder

\begin{tabular}{|c|c|c|c|c|c|c|c|c|}
\hline \multirow[b]{2}{*}{ Measure } & \multicolumn{2}{|c|}{ Headache } & \multicolumn{2}{|c|}{ Chest pain } & \multicolumn{2}{|c|}{ Stomach pain } & \multicolumn{2}{|c|}{ Joint pain } \\
\hline & Yes & No & Yes & No & Yes & No & Yes & No \\
\hline \multicolumn{9}{|l|}{ Clinician ratings } \\
\hline Panic frequency $(0-4)$ & $2.12(1.16)^{*}$ & $1.56(0.98)$ & $2.12(1.17)$ & $1.74(1.07)$ & $2.16(1.08)$ & $1.79(1.11)$ & $2.00(1.18)$ & $1.82(1.09)$ \\
\hline Panic intensity $(0-4)$ & $2.78(0.97)$ & $2.60(0.96)$ & $2.74(1.01)$ & $2.67(0.95)$ & $2.93(0.90)$ & $2.61(0.97)$ & $2.77(0.94)$ & $2.67(0.98)$ \\
\hline Anticipatory anxiety (0-4) & $2.19(1.28)$ & $2.18(1.12)$ & $2.46(1.33)$ & $2.04(1.12)$ & $2.50(1.25)$ & $2.08(1.19)$ & $2.25(1.31)$ & $2.16(1.18)$ \\
\hline $\begin{array}{l}\text { Avoidance of situations } \\
(0-4)\end{array}$ & $2.00(1.33)$ & $1.95(1.24)$ & $1.93(1.34)$ & $2.00(1.27)$ & $2.33(1.15)$ & $1.89(1.30)$ & $1.94(1.28)$ & $1.98(1.29)$ \\
\hline $\begin{array}{l}\text { Avoidance of sensations } \\
(0-4)\end{array}$ & $1.84(1.34)$ & $1.85(1.24)$ & $2.21(1.26)^{\star}$ & $1.65(1.24)$ & $2.33(1.22)^{*}$ & $1.71(1.24)$ & $1.76(1.25)$ & $1.87(1.31)$ \\
\hline Work impairment (0-4) & $1.72(1.18)$ & $1.28(1.10)$ & $1.74(1.13)$ & $1.42(1.16)$ & $1.46(1.07)$ & $1.53(1.19)$ & $1.62(1.19)$ & $1.48(1.15)$ \\
\hline Social impairment (0-4) & $1.76(1.25)$ & $1.60(1.16)$ & $1.70(1.24)$ & $1.68(1.20)$ & $1.93(1.17)$ & $1.63(1.21)$ & $1.65(1.10)$ & $1.70(1.25)$ \\
\hline \multicolumn{9}{|l|}{ Self-report ratings } \\
\hline SPRAS (0-140) & $63.4(28.0)^{*}$ & $43.4(26.6)$ & $70.4(27.5)^{\star}$ & $46.0(26.4)$ & $66.5(28.2)^{\star}$ & $51.0(28.6)$ & $61.9(32.8)$ & $52.0(27.4)$ \\
\hline MI-Accompanied $^{\dagger}(1-5)$ & $1.73(0.71)$ & $1.59(0.60)$ & $1.68(0.70)$ & $1.66(0.66)$ & $1.87(0.71)$ & $1.62(0.65)$ & $1.72(1.51)$ & $1.72(0.70)$ \\
\hline Ml-Alone ${ }^{\ddagger}(1-5)$ & $2.27(0.99)$ & $1.96(0.93)$ & $2.21(1.00)$ & $2.09(0.96)$ & $2.37(1.02)$ & $2.07(0.95)$ & $1.89(0.97)$ & $2.21(0.96)$ \\
\hline Disability§ (1-5) & $3.75(0.96)$ & $3.31(1.06)$ & $3.59(0.94)$ & $3.55(1.07)$ & $3.63(0.96)$ & $3.55(1.04)$ & $3.51(1.12)$ & $3.57(1.00)$ \\
\hline BDI $(0-63)$ & $18.5(10.9)^{*}$ & $11.9(8.0)$ & $19.9(11.4)^{*}$ & $13.4(8.9)$ & $19.9(10.2)^{*}$ & $14.4(10.0)$ & $18.0(10.1)$ & $14.9(10.2)$ \\
\hline
\end{tabular}

Values are means (SD). Clinician measures were derived from the Multicenter - Panic Anxiety scale. ${ }^{*}$ Significant group difference $(P<0.01)$ within a pain domain; tWhen Accompanied subscale of the Mobility Inventory for Agoraphobia; $¥$ When Alone subscale of The Mobility Inventory for Agoraphobia; $\$$ Sheehan Disability Scale - Work and Social Disability subscale. BDI Beck Depression Inventory; SPRAS Sheehan Patient-rated Anxiety Scale

that panic would lead to threat (PAI-2: $\mathrm{r}=0.23, \mathrm{P}<0.01)$. In terms of perceived threat, pain was significantly associated with the PAI subscale measuring physical threat $(\mathrm{r}=0.22$, $\mathrm{P}<0.01$ ), but not social or loss of control threats.

Results of the specificity analyses for pain domains and cognitive variables are displayed in Table 2 . These analyses indicate that headache and chest pain were primarily responsible for the overall associations with the cognitive measures, whereas joint and stomach pain were not significantly associated with any of the cognitive measures. Chest pain was associated with anxiety sensitivity and the physical threat subdomain of the PAI, and headache was associated with anxiety sensitivity.

Mediation of the relation between anxiety and pain Whether panic-related cognitive variables mediate the relation between anxiety and pain was tested through a series of regression analyses in accordance with the methodology outlined by Baron and Kenny (47). For mediation to occur, there must be a significant relation between the mediating variable (panic-related cognition) and the criterion variable (pain), with a simultaneous reduction in the effect of the predictor variable (anxiety) on the criterion variable. Results of analyses using the ASI suggest that anxiety sensitivity does not mediate this relation (Table 3). Similar analyses were conducted using the PAI subscales and showed essentially the same pattern of findings. Thus, there is little evidence to suggest that cognitive variables mediate the relation between anxiety and pain.

\section{Pain and treatment outcome}

Using a subset of patients $(\mathrm{n}=77)$ who underwent treatment or a delayed treatment control condition, the authors assessed whether pain moderated treatment outcome for patients participating in a 10-week cognitive behavioural treatment protocol (48). Because the primary interest was in investigating moderator effects, analyses were conducted in the following manner. By following the procedures outlined by Cohen and Cohen (49), a regression-based approach was used with the baseline covariate (corresponding to the outcome measure of interest), along with main effects for treatment condition (treatment, control) and the moderator variable (yes or no for each pain domain), followed by the interaction term represented by the product of the two main effects (eg, treatment $\times$ moderator). Ethnicity was also entered as a covariate for analyses evaluating headache. To simplify these analyses, the two active cognitive behavioural treatment groups were collapsed and compared with the delayed treatment control group. The outcome measures selected for investigation captured the main clinical features of panic disorder, including anxiety (SPRAS), phobic avoidance (MI-Alone and MI-Accompanied) and panic attack frequency (CY-PAS-1). These analyses produced no signifi- 
TABLE 2

Relation between pain endorsement and cognitive features in patients with panic disorder

\begin{tabular}{|c|c|c|c|c|c|c|c|c|}
\hline \multirow[b]{2}{*}{ Measure } & \multicolumn{2}{|c|}{ Headache } & \multicolumn{2}{|c|}{ Chest pain } & \multicolumn{2}{|c|}{ Stomach pain } & \multicolumn{2}{|c|}{ Joint pain } \\
\hline & Yes & No & Yes & No & Yes & No & Yes & No \\
\hline Anxiety Sensitivity Index (0-64) & $\begin{array}{l}31.9 \\
(11.2)^{*}\end{array}$ & $\begin{array}{c}26.9 \\
(10.7)\end{array}$ & $\begin{array}{l}33.7 \\
(11.6)^{\star}\end{array}$ & $\begin{array}{c}27.6 \\
(10.5)\end{array}$ & $\begin{array}{c}32.6 \\
(11.2)\end{array}$ & $\begin{array}{c}28.8 \\
(11.1)\end{array}$ & $\begin{array}{c}30.6 \\
(12.4)\end{array}$ & $\begin{array}{c}29.4 \\
(10.8)\end{array}$ \\
\hline PAI-Likelihood ${ }^{\dagger}$ (0-1500) & $\begin{array}{c}567.5 \\
(301.1)\end{array}$ & $\begin{array}{c}445.8 \\
(292.9)\end{array}$ & $\begin{array}{c}566.6 \\
(308.3)\end{array}$ & $\begin{array}{c}488.5 \\
(298.2)\end{array}$ & $\begin{array}{c}616.6 \\
(295.1)\end{array}$ & $\begin{array}{c}485.5 \\
(300.9)\end{array}$ & $\begin{array}{c}479.9 \\
(310.1)\end{array}$ & $\begin{array}{l}524.4 \\
(300.4)\end{array}$ \\
\hline $\begin{array}{l}\text { PAI-Consequences }{ }^{\ddagger} \\
\text { - Overall }(0-1500)\end{array}$ & $\begin{array}{c}555.1 \\
(350.9)\end{array}$ & $\begin{array}{c}419.4 \\
(365.8)\end{array}$ & $\begin{array}{l}585.0 \\
(326.2)\end{array}$ & $\begin{array}{c}448.9 \\
(375.2)\end{array}$ & $\begin{array}{c}509.0 \\
(349.2)\end{array}$ & $\begin{array}{c}488.4 \\
(369.2)\end{array}$ & $\begin{array}{l}598.1 \\
(334.3)\end{array}$ & $\begin{array}{c}459.2 \\
(366.8)\end{array}$ \\
\hline $\begin{array}{l}\text { PAI-Consequences } \\
\text { - Physical (0-500) }\end{array}$ & $\begin{array}{c}191.6 \\
(143.4)\end{array}$ & $\begin{array}{c}136.9 \\
(136.3)\end{array}$ & $\begin{array}{c}226.1 \\
(141.8)^{*}\end{array}$ & $\begin{array}{c}138.0 \\
(134.3)\end{array}$ & $\begin{array}{c}165.6 \\
(140.1)\end{array}$ & $\begin{array}{c}165.6 \\
(142.7)\end{array}$ & $\begin{array}{c}184.2 \\
(130.4)\end{array}$ & $\begin{array}{c}161.5 \\
(146.4)\end{array}$ \\
\hline $\begin{array}{r}\text { PAI-Consequences } \\
\text { - Social (0-500) }\end{array}$ & $\begin{array}{c}192.9 \\
(142.7)\end{array}$ & $\begin{array}{c}144.8 \\
(157.2)\end{array}$ & $\begin{array}{c}179.7 \\
(138.4)\end{array}$ & $\begin{array}{c}167.2 \\
(158.1)\end{array}$ & $\begin{array}{c}179.0 \\
(138.7)\end{array}$ & $\begin{array}{c}171.0 \\
(154.3)\end{array}$ & $\begin{array}{c}201.5 \\
(147.3)\end{array}$ & $\begin{array}{r}161.3 \\
(151.2)\end{array}$ \\
\hline $\begin{array}{l}\text { PAI-Consequences } \\
\quad \text { - Loss of Control (0-500) }\end{array}$ & $\begin{array}{c}169.2 \\
(144.2)\end{array}$ & $\begin{array}{c}138.3 \\
(152.0)\end{array}$ & $\begin{array}{c}176.2 \\
(144.5)\end{array}$ & $\begin{array}{c}143.5 \\
(149.9)\end{array}$ & $\begin{array}{c}167.6 \\
(147.0)\end{array}$ & $\begin{array}{c}150.8 \\
(149.0)\end{array}$ & $\begin{array}{c}210.5 \\
(168.6)\end{array}$ & $\begin{array}{c}136.8 \\
(136.3)\end{array}$ \\
\hline PAI-Coping§ (0-1500) & $\begin{array}{c}500.3 \\
(288.1)\end{array}$ & $\begin{array}{c}612.2 \\
(330.8)\end{array}$ & $\begin{array}{c}505.7 \\
(293.6)\end{array}$ & $\begin{array}{c}573.3 \\
(321.6)\end{array}$ & $\begin{array}{c}564.7 \\
(503.1)\end{array}$ & $\begin{array}{c}564.7 \\
(328.5)\end{array}$ & $\begin{array}{c}488.4 \\
(323.0)\end{array}$ & $\begin{array}{l}571.7 \\
(306.7)\end{array}$ \\
\hline
\end{tabular}

Values are means $(S D)$. ${ }^{*}$ Significant group difference $(P<0.01)$ within a pain domain; 'Subscale of the Pain Appraisal Inventory $(P A I)$ assessing panic likelihood across a variety of settings; ₹Subscale of the PAI assessing perceived catastrophic consequences of experiencing panic; ${ }^{\$}$ Subscale of the PAI assessing coping selfefficacy in the context of panic

TABLE 3

Regression analyses testing mediation effects of anxiety sensitivity on the relation between anxiety and pain

\begin{tabular}{|c|c|c|c|c|c|}
\hline $\begin{array}{l}\text { Dependent } \\
\text { variable }\end{array}$ & Step & $\begin{array}{c}\text { Independent } \\
\text { variable(s) }\end{array}$ & $\mathrm{B}^{*}$ & $\chi^{2}$ & $\mathbf{P}$ \\
\hline ASI & 1 & Anxiety (SPRAS) & 0.24 & $9.26^{\dagger}$ & $<0.0001$ \\
\hline Chest pain & 2 & Anxiety (SPRAS) & 0.03 & 14.8 & $<0.0001$ \\
\hline Headache & & Anxiety (SPRAS) & 0.03 & 18.9 & $=0.0001$ \\
\hline Stomach pain & & Anxiety (SPRAS) & 0.02 & 6.30 & $<0.05$ \\
\hline Joint pain & & Anxiety (SPRAS) & 0.01 & 3.02 & $=0.08$ \\
\hline \multirow[t]{2}{*}{ Chest pain } & 3a & Anxiety (SPRAS) & 0.03 & 11.8 & $<0.001$ \\
\hline & & ASI & 0.00 & 0.00 & - \\
\hline \multirow[t]{2}{*}{ Headache } & $3 b$ & Anxiety (SPRAS) & 0.03 & 9.52 & $<0.01$ \\
\hline & & ASI & 0.00 & 0.04 & - \\
\hline \multirow[t]{2}{*}{ Stomach pain } & $3 c$ & Anxiety (SPRAS) & 0.02 & 3.74 & $=0.06$ \\
\hline & & ASI & 0.00 & 0.01 & - \\
\hline \multirow[t]{2}{*}{ Joint pain } & $3 d$ & Anxiety (SPRAS) & 0.01 & 3.10 & $=0.08$ \\
\hline & & ASI & 0.01 & 0.51 & - \\
\hline
\end{tabular}

Anxiety was regressed separately on each dependent variable in steps 1 and 2 , but in step 3, anxiety was simultaneously regressed with Anxiety Sensitivity Index (ASI) scores *Unstandardized estimate; ${ }^{t} t$ ratio. SPRAS Sheehan Patient-Rated Anxiety Scale cant interaction terms, suggesting that pain symptoms do not significantly moderate treatment response for patients undergoing cognitive behavioural treatment.

\section{DISCUSSION}

The purpose of the present report was to expand our knowledge of the interrelationships between pain and anxiety symptoms among patients with panic disorder. Consistent with previous reports, pain was endorsed in a high percentage of patients. Also consistent with other reports was the high level of endorsement of headache and chest pain. It is notable, however, that stomach and joint pain were also fairly prevalent in this sample, suggesting that these patients had a wide range of pain experiences. In the present report, pain endorsement was somewhat higher than that in previous studies, likely because of the nature of the measures (10). Kuch et al (10) assessed chronic pain (longer than six months), which we presume would be less likely to be endorsed than current pain symptoms. One limitation of our data is that we did not have a nonclinical comparison sample. Thus, we cannot determine whether this level of pain endorsement is higher than that of the general population. However, in a recent study, patients with anxiety disorders reported higher levels of pain than patients with chronic pain (50). These data suggest that patients with anxiety are likely to have elevated pain relative to nonclinical samples, but future research should assess this hypothesis directly.

Results of our analyses examining the relation between pain and anxiety symptoms are somewhat consistent with 
those of earlier reports. Pain was associated with general symptoms of anxiety and depression - similar to the results found by Kuch et al (10). However, unlike Kuch et al (10), we did not find an association with phobic avoidance. Differences in the type of pain assessed (chronic versus current) may account for this discrepancy. Relative to our measure of current pain, we suspect that endorsement of chronic pain is likely to be indicative of more severe pain symptoms that would have a greater impact on avoidance in terms of the mechanisms outlined by Asmundson and Taylor (28). The present report provides a more detailed assessment of other types of panic symptoms (eg, panic frequency, anticipatory anxiety, avoidance of sensations), and a number of other associations were found. However, both studies generally suggest that pain is more closely linked with general negative affect symptoms such as anxiety and depression.

Results of the pain-anxiety symptom specificity analyses were consistent with the expected results. Of the types of pain studied, joint pain was least associated with anxiety, whereas headache and chest pain were most highly associated with anxiety. This is not surprising given the amount of attention given to chest pain and headache (to a lesser extent) in panic disorder. As noted above, these data are consistent with cognitive theories of panic and panic disorder to the extent that these models suggest the importance of immediate catastrophic misinterpretation of bodily perturbations $(51,52)$. Thus, patients with panic disorder are prone to associate chest pain with cardiovascular threats such as heart attack, and headaches may be associated with stroke; however, joint pain is less likely to be associated with some imminent danger.

The cognitive model of panic assumes that pain contributes to anxiety. The opposite relation may also be relevant. Anxiety symptoms may dispose individuals toward greater pain (53-55). More specifically, Weisenberg et al (56) proposed that anxiety that is relevant to the pain-inducing stimulus exacerbates pain, whereas anxiety that is irrelevant to pain reduces pain. For example, dental phobics show no differences in pain tolerance to arm shock but significant differences to tooth shock relative to control subjects (57). Likewise, subjects given anxiety-producing information about a cold pressor report greater pain to the cold pressor than those given anxiety-producing information about other (irrelevant) tasks (58). Of course, the cross-sectional nature of the data in the present study does not allow causal or sequential inferences. Pain and anxiety symptoms may interact reciprocally, with each contributing to the other, in some patients with panic disorder, creating a vicious cycle.

We found pain to be associated with anxiety sensitivity as well as several appraisal variables, including increased physical threat appraisal and decreased coping with panic - consistent with the results of the study by Kuch et al (10). We cannot determine the nature of this relation from the present data, but it seems reasonable to assume that patients experiencing pain in certain domains would be more likely to develop threatening appraisals that are relevant to the pain symptoms. For example, theories of anxiety sensitivity indicate that these beliefs are learned, with pain experiences providing an opportunity to focus on these sensations and potentially worry about their meaning (59). After such beliefs are developed, we would expect to see elevations in measures of anxiety sensitivity, hypervigilance to pain sensations and avoidance of sensations that are deemed threatening (27). This sequence of events is also consistent with the specific association found between chest and stomach pain, and the avoidance of bodily sensations.

Having described a possible set of associations among pain, cognitive variables and anxiety, it is important to note that this more complex set of relations was not supported by the particular cognitive measures that we used. Results of the mediator analyses suggest that our cognitive measures have little role in mediating the relation between anxiety and pain. These cross-sectional findings are not consistent with those of an earlier experimental study showing that anxiety sensitivity partially mediated the relation between diagnostic status (panic disorder versus control) and pain symptoms (18). Differences in study methodology likely contributed to these discrepancies; however, this set of findings highlights the fact that other, unmeasured variables (such as fear of pain, hypervigilance or attentional bias, and physiological parameters including genetic factors), play an important role in mediating the relation between pain and anxiety in these patients (28). It is also worth noting that many significant relations reported in the present article describe associations between pain and anxiety symptoms that account for only a limited amount of the common variance. Clearly, additional work is needed to clarify the complicated array of relations that exist between pain and anxiety.

The last set of analyses evaluated whether pain symptoms affected the effectiveness of cognitive behavioural treatment for panic disorder. There was little suggestion that pain moderates treatment outcome. One limitation of the study that is likely to have affected this conclusion is our failure to measure pain severity. It is conceivable that patients who are more severely debilitated by pain will have poorer outcomes. Anecdotally, we recall two patients in the present trial who showed extreme and chronic pain symptoms. Both were accident victims who were disabled at the time of treatment because of injury or pain resulting from the accidents. Each of these patients showed excellent recovery from their panic disorder. However, conclusions about the moderating effects of pain in the context of cognitive behavioural treatment should be tempered until this issue is studied in more detail. Moreover, we encourage therapists to address the possible relations between anxiety and pain in patients experiencing significant pain symptoms because it may be useful for some patients to be aware of this process. It would also be useful for medical professionals dealing primarily with pain syndromes to be aware of the relation between anxiety and pain, as well as of the fact that some individuals, such as those with panic disorder, are likely to present for painrelated treatment. It is especially important for these professionals to be aware of the interplay between anxiety and pain in this subset of patients. 


\section{REFERENCES}

1. Markowitz JS, Weissman MM, Ouellette R, et al. Quality of life in panic disorder. Arch Gen Psychiatry 1989;46:984-92.

2. Boyd JH. Use of mental health services for the treatment of panic disorder. Am J Psychiatry 1986;143:1569-74.

3. Katon W. Panic disorder: Relationship to high medical utilization, unexplained physical symptoms, and medical costs. J Clin Psychiatry 1996;57:11-8.

4. Beitman BD, Mukeiji V, Flaker G, Basha IM. Panic disorder, cardiology patients and atypical chest pain. Psychiatr Clin North Am 1988;11:387-98.

5. Carter C, Maddock R, Zoglio M, Lutrin C, Jella S, Amsterdam E. Panic disorder and chest pain: A study of cardiac stress scintigraphy patients. Am J Cardiol 1994;74:296-8.

6. Madland G, Feinmann C, Newman S. Factors associated with anxiety and depression in facial arthromyalgia. Pain 2000;84:225-32.

7. Vlaeyen JWS, Linton SJ. Fear-avoidance and its consequences in chronic musculoskeletal pain: a state of the art. Pain 2000;85:317-32.

8. Bond MR, Pilwsky I. Subjective assessment of pain and its relationship to the administration of analgesics in patients with advanced cancer. J Psychosom Res 1966;10:203-8.

9. Bond MR, Glynn JP, Thomas DG. The relation between pain and personality in patients receiving pentazocine (Fortral) after surgery. J Psychosom Res 1976;20:369-81.

10. Kuch K, Cox BJ, Woszczyna CB, Swinson RP, Shulman I. Chronic pain in panic disorder. J Behav Ther Exp Psychiatry 1991;22:255-9.

11. Carter C, Maddock R, Amsterdam E, McCormick S, Waters C, Billett J. Panic disorder and chest pain in the coronary care unit. Psychosomatics 1992;33:302-9.

12. Wulsin LR, Hilliard JR, Geier P, Hissa D, Rouan GW. Screening emergency room patients with atypical chest pain for depression and panic disorder. Int J Psychiatry Med 1988;18:315-23.

13. Chambers J, Bass C. Chest pain with normal coronary anatomy: A review of natural history and possible etiologic factors. Prog Cardiovasc Dis 1990;33:161-84.

14. Dougher MJ. Sensory decision theory analysis of the effects of anxiety and experimental instructions on pain. J Abnorm Psychol 1979;88:137-44.

15. Malow RM. The effects of induced anxiety on pain perception: A signal detection analysis. Pain 1981;11:397-405.

16. Schumacher R, Velden M. Anxiety, pain experience, and pain report: A signal-detection study. Percept Mot Skills 1984;58:339-49.

17. Roy-Burne P, Uhde TW, Post RM, King AC, Buchsbaum MS. Normal pain sensitivity in patients with panic disorder. Psychiatry Res 1985; $14: 75-82$.

18. Schmidt NB, Cook JH. Effects of anxiety sensitivity on anxiety and pain during a cold pressor challenge in patients with panic disorder. Behav Res Ther 1999;37:313-23.

19. Reiss S, McNally RJ. The expectancy model of fear. In: Reiss S, Bootzin RR, eds. Theoretical Issues in Behavior Therapy. New York: Academic Press, 1985:107-21.

20. Reiss S, Havercamp SM. Toward a comprehensive assessment of fundamental motivation: Factor structure of the Reiss profiles. Psychol Assess 1998;10:97-106

21. Donnell CD, McNally RJ. Anxiety sensitivity and panic attacks in a nonclinical population. Behav Res Ther 1990;28:83-5.

22. Schmidt NB, Lerew DR, Jackson RJ. The role of anxiety sensitivity in the pathogenesis of panic: Prospective evaluation of spontaneous panic attacks during acute stress. J Abnorm Psychol 1997;106:355-64.

23. Schmidt NB, Lerew DR, Jackson RJ. Prospective evaluation of anxiety sensitivity in the pathogenesis of panic: Replication and extension. J Abnorm Psychol 1999;108:532-7.

24. Asmundson GJ, Jacobson SJ, Allerdings MD, Norton GR. Social phobia in disabled workers with chronic musculoskeletal pain.

Behav Res Ther 1996;34:939-43.

25. Craig KD. Emotional aspects of pain. In: Wall PD, Melzack R, eds. The Textbook of Pain. Edinburgh: Churchill Livingstone, 1994:261-74.

26. Schmidt NB, Telch MJ. Nonpsychiatric medical comorbidity, health perceptions, and treatment outcome in patients with panic disorder. Health Psychol 1997;16:114-22.

27. Asmundson GJ, Kuperso JL, Norton GR. Do patients with chronic pain selectively attend to pain-related information?: preliminary evidence for the mediating role of fear. Pain 1997;72:27-32.

28. Asmundson GJ, Taylor S. Role of anxiety sensitivity in pain-related fear and avoidance. J Behav Med 1996;19:577-86.

29. Fordyce WE. Behavioral Methods for Chronic Pain and Illness. St Louis: Mosby, 1976.
30. Lethem J, Slade PD, Troup JDG, Bentley G. Outline of a fearavoidance model of exaggerated pain perception-I. Behav Res Ther 1983;21:401-8.

31. Philips $H$. Avoidance behavior and its role in sustaining chronic pain. Behav Res Ther 1987;25:273-9.

32. Asmundson GJ, Norton PJ, Norton GR. Beyond pain: The role of fear and avoidance in chronicity. Clin Psychol Rev 1999;19:97-119.

33. Schmidt NB, Koselka M. Gender differences in patients with panic disorder: Evaluating mediation of phobic avoidance. Cogn Ther Res 2000;24:531-48.

34. American Psychiatric Association. Diagnostic and Statistical Manual of Mental Disorders, 4th edn. Washington: American Psychiatric Press, 1994.

35. First MB, Spitzer RL, Gibbon M, Williams JBW. Structured Clinical Interview for Axis I DSM-IV Disorders-Patient Edition, version 2.0. New York: Biometrics Research Department, 1994.

36. Schmidt NB, Staab JP, Trakowski JH Jr, Sammons M. Efficacy of a brief psychsocial treatment for panic disorder in an active duty sample: Implications for military readiness. Mil Med 1997;162:123-9.

37. Schmidt NB, Trakowski JH Jr, Staab JP. Extinction of panicogenic effects of a $35 \% \mathrm{CO}_{2}$ challenge in patients with panic disorder. J Abnorm Psychol 1997;106:630-8.

38. Shear MK, Brown TA, Barlow DH, et al. Multicenter collaborative panic disorder severity scale. Am J Psychiatry 1997;154:1571-5.

39. Sheehan DV. The Anxiety Disease. New York: Scribners, 1983.

40. Chambless DL, Caputo CG, Jasin SE, Gracely EJ, Williams C. The mobility inventory for agoraphobia. Behav Res Ther 1985;23:35-44.

41. Ballenger JC, Burrows GD, DuPont RL Jr, et al. Alprazolam in panic disorder and agoraphobia: Results from a multicenter trial: I. Efficacy in short-term treatment. Arch Gen Psychiatry 1988;45:413-22.

42. Beck AT, Steer RA. Beck Depression Inventory. San Antonio: The Psychological Corporation, 1993.

43. Peterson RA, Reiss S. Test Manual for the Anxiety Sensitivity Index. Orland Park: International Diagnostic Systems, 1987.

44. McNally RJ. Panic Disorder: A Critical Analysis. New York: Guilford Press, 1994.

45. Schmidt NB, Telch MJ, Joiner TE Jr. Factory influencing health perceptions in patients with panic disorder. Compr Psychiatry 1996;37:253-60.

46. Telch MJ, Brouillard M, Telch CF, Agras WS, Taylor CB. Role of cognitive appraisal in panic-related avoidance. Behav Res Ther 1989;27:373-83.

47. Baron RM, Kenny DA. The moderator-mediator variable distinction in social psychological research: Conceptual, strategic, and statistical considerations. J Pers Soc Psychol 1986;51:1173-82.

48. Schmidt NB, Woolaway-Bickel K, Trakowski J, et al. Dismantling cognitive-behavioral treatment for panic disorder: Questioning the utility of breathing retraining. J Consult Clin Psychol 2000;68:417-24

49. Cohen J, Cohen P. Applied Multiple Regression/Correlation Analysis for the Behavioral Sciences, 2nd edn. Hillsdale: Lawrence Erlbaum Associates, 1983.

50. Asmundson GJG, Walker JR, Furer P, Kjernisted K. Beyond anxiety: A preliminary look at acute and chronic pain in individuals seeking treatment for anxiety disorders. The 20th annual meeting of the Anxiety Disorders Association of America, Washington, March 23-26 2000.

51. Clark DM. A cognitive approach to panic. Behav Res Ther $1986 ; 24: 461-70$

52. Barlow D. Anxiety and its Disorders: The Nature and Treatment of Anxiety and Panic. New York: Guilford Press, 1988.

53. Gross RT, Collins FL Jr. On the relationship between anxiety and pain: A methodological confounding. Clin Psychol Rev 1981;1:375-86.

54. Leventhal H, Everhart D. Emotion, pain, and physical illness. In: Izard CE, ed. Emotions and Psychopathology. New York: Plenum Press, 1979:263-99.

55. Weisenberg M. Psychological intervention for the control of pain. Behav Res Ther 1987;25:301-12

56. Weisenberg M, Aviram O, Wolf Y, Raphaeli N. Relevant and irrelevant anxiety in the reaction to pain. Pain 1984;20:371-83.

57. Klepac RK, McDonald M, Hauge G, Dowling J. Reactions to pain among subjects high and low in dental fear. J Behav Med 1980;3:373-84.

58. Absi MA, Rokke PD. Can anxiety help us tolerate pain? Pain 1991;46:43-51.

59. Reiss S. Expectancy model of fear, anxiety, and panic. Clin Psychol Rev 1991;11:141-53. 


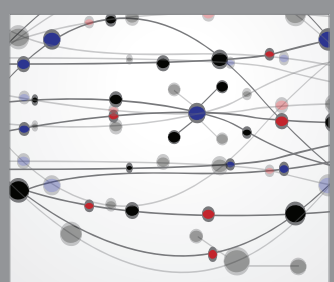

The Scientific World Journal
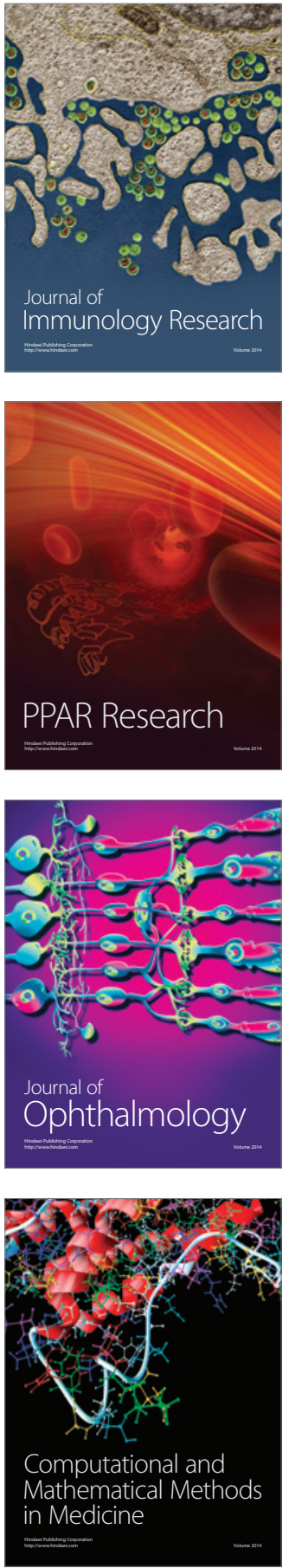

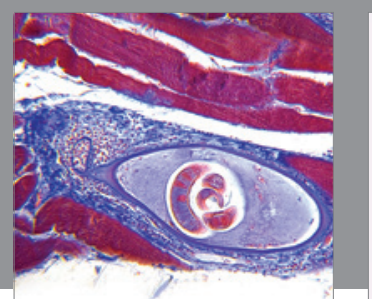

Gastroenterology Research and Practice

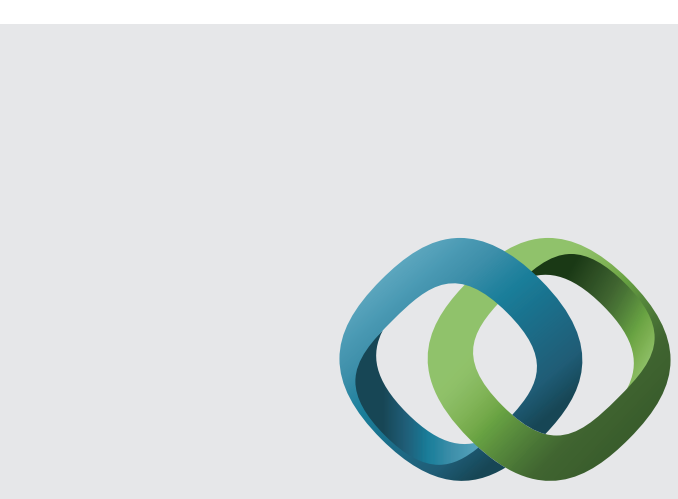

\section{Hindawi}

Submit your manuscripts at

http://www.hindawi.com
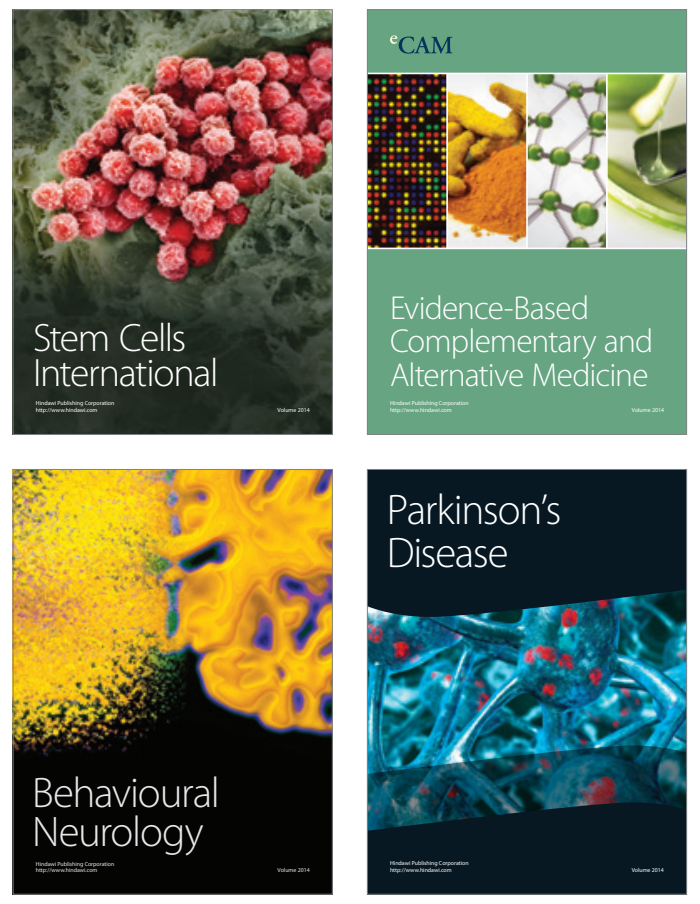
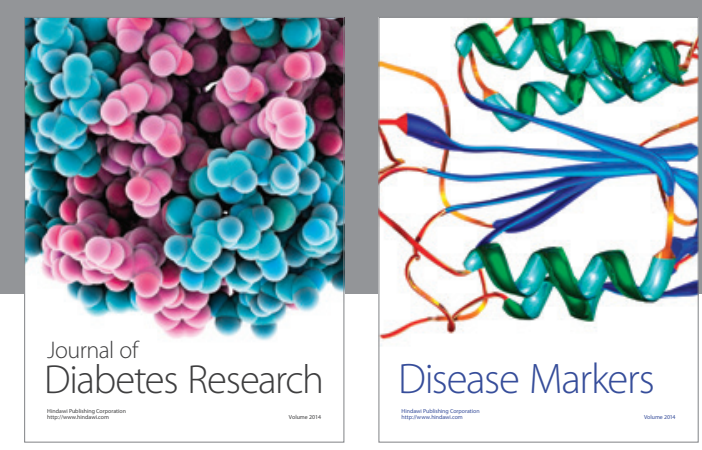

Disease Markers
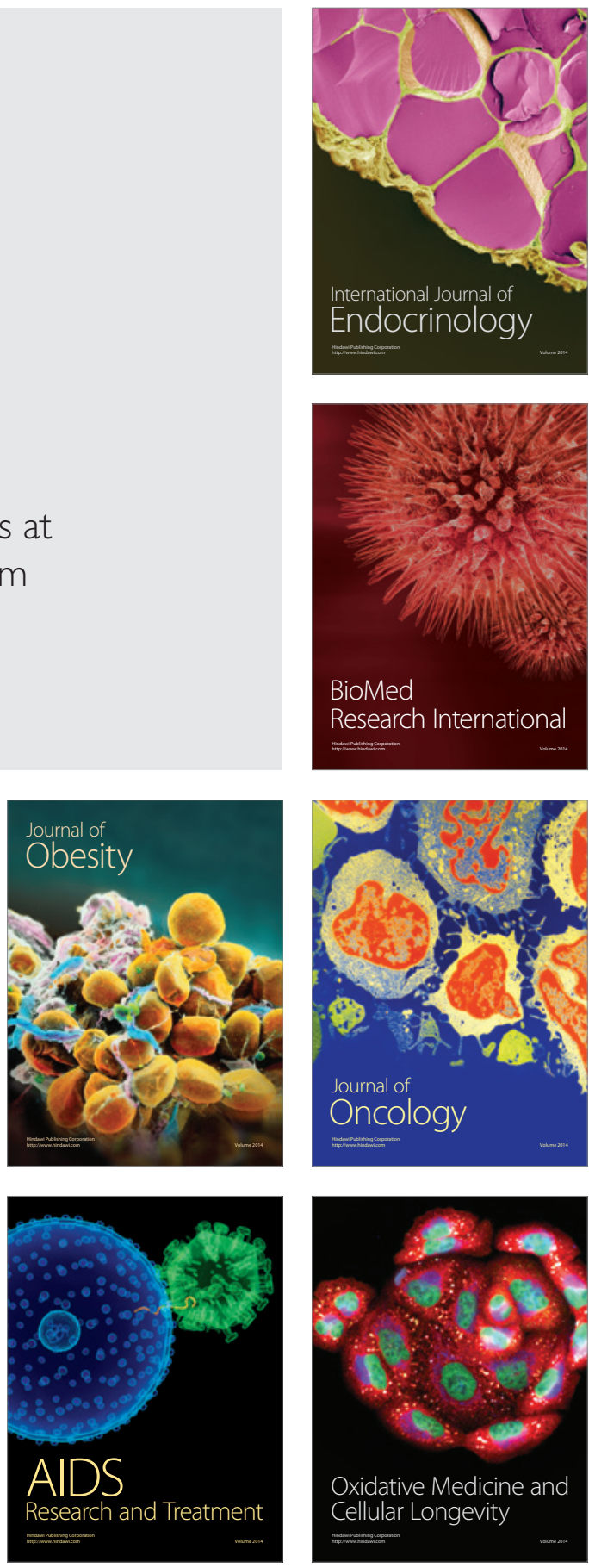